\title{
Conservation: the hopes and the fears
}

\section{Brian Bertram}

Conservation Biology: An EvolutionaryEcological Perspective. Edited by Michael E. Soulé and Bruce A. Wilcox. Pp.395. (Addison-Wesley/Sinauer: 1980.) Pbk £7.95, \$14.50.

THIS will be a disturbing book to anyone who believes that conservation is a matter merely of defining and protecting a number of reserve areas which are representative of ecosystems being destroyed. Michael Soulé and Bruce Wilcox have gathered a fine series of papers demonstrating the vast problems ahead of us all, and showing what we can expect the results of our conservation efforts to be.

Part I contains four chapters on the ecological principles of conservation. They concentrate on tropical forests, which are particularly vulnerable and of which it is likely that two-thirds will have disappeared within a mere 20 years. These early contributions by Gilbert, Eisenberg, Diamond and Foster, show what it is that we risk losing - a fabulously intricate set of interactions among plants and animals, varying both with locality and over time. We are clearly shown that small isolated "representative" portions of the vanishing tropical forests do not contain or cannot maintain more than a fraction of the species of the whole area represented.

Isolated reserves dotted about in a barren waste of altered or destroyed habitat act like islands; the five chapters in Part II consider the consequences of this "insularization" (horrid word). It is well known that true islands generally contain fewer species than the adjacent mainland, and a frequent cause is that the small populations on small islands are highly vulnerable to extinction. Recolonization depends on accessibility from other land areas. Wilcox, and Terborgh and Winter, draw on principles from insular ecology and extrapolate to isolated reserves.

Even if they do not become extinct, small populations face unusual evolutionary problems, as is shown in Franklin's and Soulé's chapters. They are subject to genetic drift, and they contain only a limited amount of genetic variability with which to respond to selection pressures. The level of inbreeding among members of the small population rises, fixing deleterious recessive genes and resulting in higher mortality, lower fecundity and distorting the sex ratio towards surplus males. Two particularly important conclusions emerge. First, that the effective population size must be not less than about 50 individuals to keep inbreeding to a level low enough for the population to survive. Second, that in Soule's words "significant evolutionary change in most higher organisms is coming to a screeching halt in the tropics".
Part III, on captive propagation and conservation, deals with the similarly small populations which can be kept and bred in zoos. Some species can certainly be preserved in captivity even when extinct in the wild. But, as Conway shows, all the zoos in the USA together contain only enough space for viable populations of about 200 species of mammals. Coordination among zoos is required and is growing, but recognition by society of their important role is far too slow. Benirschke and colleagues describe some of the variety of modern aids in captive propagation, and Kleiman surveys the application of sociobiological study to animals in captivity; both enable greater breeding potential to be realized. Successful reintroduction to the wild is the ultimate and difficult objective, and Campbell reviews the numerous problems involved and the successes achieved.

The final section in the book deals with exploitation and strategies of conservation. Coe examines ecological interactions between human beings and wildlife in Africa, and assesses the present and future importance of game hunting, pastoralism, the tsetse fly, tourism, and the prospects for the culling, ranching and domestication of wild species of mammal. With Kenya's population now increasing at $4 \%$ per year, major problems are looming fast. Whitmore describes the extent and consequences of the destructive exploitation of tropical forests - some 50 hectares have been destroyed and disappeared while you have been reading this review, and another 30 will have gone before you finish. The direct effect on local species of animal is obvious; the indirect effects on all animals everywhere, because of the climatic changes caused, are unknown.

What we should do is the subject of the last two chapters. Pyle discusses the general management of nature reserves in the developed world. But that is not where most of the problem lies, although many of the causes of the problem do, according to Ehrlich. Human population growth threatens all tropical habitats; but so too does economic growth or the expectation of it. The Amazon forests are being erased only partly to provide living land for burgeoning Brazilians but also to provide timber and beef for North America and Europe. Ehrlich urges us to initiate and follow a more aggressive and wider conservation strategy. We must not be misled by the relatively slow rate of habitat loss in our own countries.

The papers in this book are diverse in character, but they all point very clearly in one direction. The editors summarize it eloquently:

The green mantle of Earth is now being ravaged and pillaged in a frenzy of exploitation by a mushrooming mass of humans and bulldozers. Never in the 500 million years of terrestrial evolution has this mantle we call the biosphere been under such a savage attack. . There is no escaping the conclusion that in our lifetimes, this planet will see a suspension, if not an end, to many ecological and evolutionary processes which have been uninterrupted since the beginnings of palaeontological time. We hope it is only a suspension - that the horrible onslaught can be stopped before the regenerative powers of ecosystems are killed. This book is a statement of that optimism. . . This is the challenge of the millenium. For centuries to come, our descendants will damn us or eulogize us, depending on our integrity and the integrity of the green mantle they inherit.

This book is not the uninformed emotional outburst of an eco-freak. It is a collection of the informed statements and pleas of 21 experts. But it is well written, so anyone can read it. And everyone should.

Brian Bertram is Curator of Mammals at the Zoological Society of London.

\section{Weather and water}

\section{William R. Cotton Kevin R. Knupp}

Clouds and Storms: The Behaviour and Effect of Water in the Atmosphere. By F.H. Ludlam. Pp.405 + plates. (Pennsylvania State University Press: 1980.) $£ 24.95, \$ 57.50$.

THE late Dr Frank H. Ludlam was a keen observer of nature. His ability to combine and synthesize fragments of data and thereby construct data-consistent conceptual models of weather-phenomena is unmatched in this century. In this book, Dr Ludlam focused on the various forms of water in the atmosphere as the underlying factor in controlling the unique characteristics of many weather systems.

The book is largely devoted to the observed characteristics of the physics and dynamics of convective clouds (Chapters 5,7 and 8). Discussion of topics closely related to cloud processes - radiation, atmospheric optics, atmospheric thermodynamics, atmospheric aerosol physics and cloud microphysics - in the preceding chapters serves as a "seful background. A transition chapter (6) compares the timescale and energy of clouds to related atmospheric processes. The ninth and final chapter deals with clouds associated with larger-scale systems.

The book is unique in several respects. First, it contains a copious amount of 